\title{
TO THE 85TH BIRTHDAY OF A. A. LOGUNOV
}

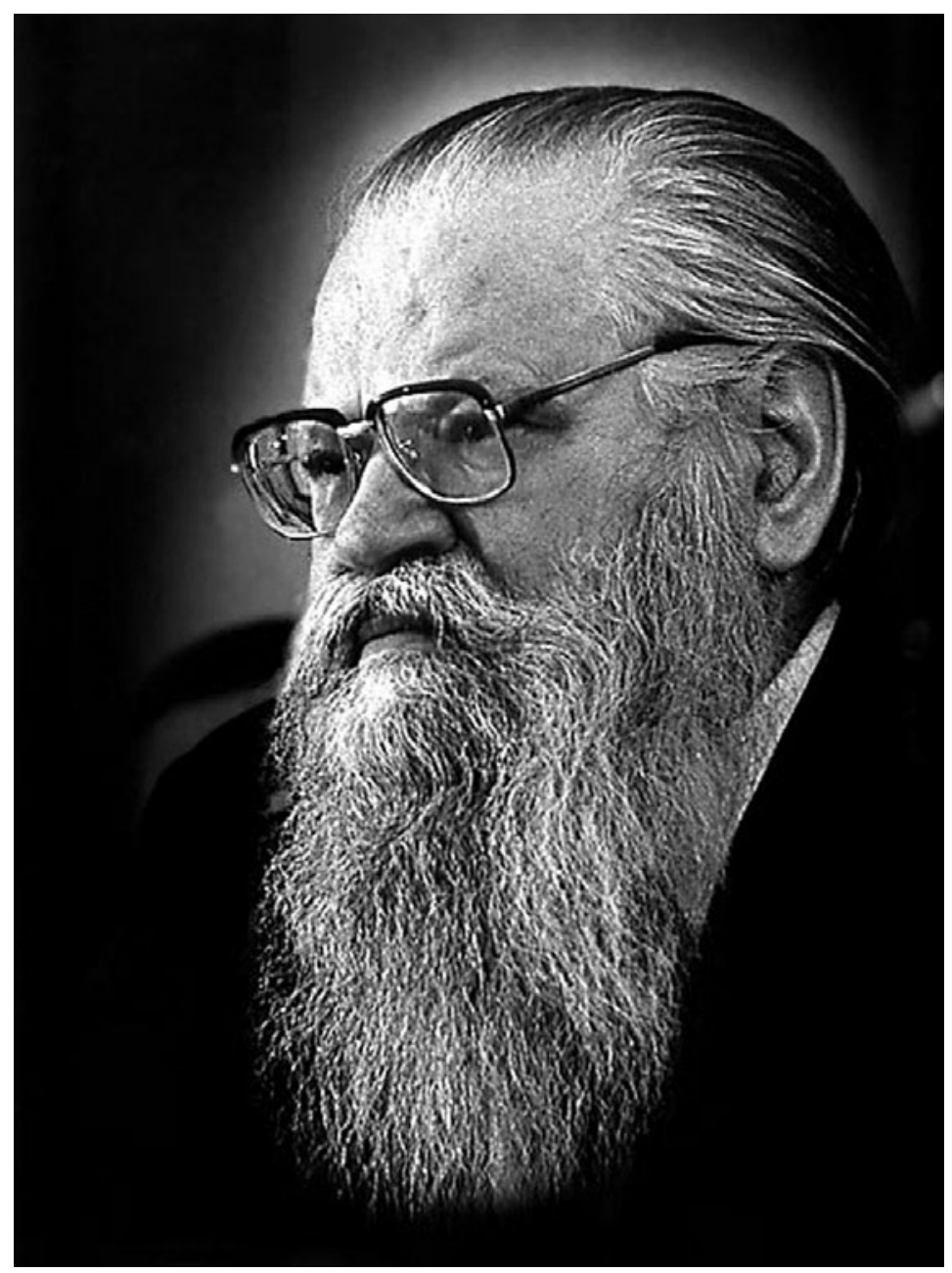

Anatoly Alekseyevich Logunov

The Editorial Board and staff of Theoretical and Mathematical Physics heartily congratulate the Chief Editor of the journal, Anatoly Alekseyevich Logunov, on his jubilee and wish him stout health, happiness, and further creative successes.

Translated from Teoreticheskaya i Matematicheskaya Fizika, Vol. 169, No. 3, pp. 339-340, December, 2011. 